\title{
O valor atual do princípio da oralidade $^{\mathrm{I}}$
}

\author{
Mauro Cappelletti"
}

1. Duas razões podem justificar esta exposição sumária do meu pensamento sobre o tema da oralidade no processo: a experiência oferecida pelo ordenamento jurídico italiano e, em especial, do código de processo civil vigente no meu país; e um amplo estudo, de publicação próxima e por mim dedicado a esse tema, no qual pude utilizar com proveito a análise de múltiplas experiências estrangeiras ${ }^{1}$.

Não existe dúvida de que, na história do pensamento e das reformas jurídicas inspiradas no princípio da oralidade, uma primeira fase resulte atualmente superada, à luz dos resultados práticos e das mais modernas elaborações doutrinárias. Era a fase dominada, por assim dizer, mais pela reação do que pela razão. Observavam-se os gravíssimos inconvenientes de um processo rigidamente inspirado no princípio da escritura, no qual valia a máxima quod non est in actis non est de hoc mundo, ou seja, a máxima da inexistência jurídica de todo ato processual que não tivesse assumido a forma escrita - escrituras, documentos, petições - e se afirmava, por isso, da maneira mais radical, a

necessidade de abolir aquele princípio para substitui-lo por outro, totalmente oposto, pelo qual o juiz poderia e deveria apreciar na sua sentença apenas os atos que tivessem sido desenvolvidos na audiência oral de instrução. Todavia, está atualmente claro que, com isso, um formalismo vinha-se a substituir um outro, ainda que oposto. Se outrora se entendia como acta somente aqueles atos que tivessem assumido a forma escrita, agora válidos e existentes eram considerados apenas os atos orais. Dessa forma, o quod non est in actis non est in mundo não era abolido, mas conservado, com a simples transformação do significado do substantivo: acta como atos orais, em lugar de escritos. Daí, novos inconvenientes gravíssimos, novos formalismos vazios. As partes ou os seus defensores, que deveriam repetir oralmente (geralmente com a vedação de sustentar seu discurso na leitura da escrita ou de apontamentos) na audiência de instrução, as argumentações que já estavam exaurientemente expostas nas petições; a necessidade quoad substantiam de expressar-se oralmente, naquela audiência,

1 Trabalho traduzido por Daniel Ustárroz, advogado, com autorização da editora Giuffrè, conforme originais publicados in Annali dell'Università di Macerata. Milano: Giuffrè, 1960. Revisto pelo Professor Carlos Alberto Alvaro de Oliveira, a quem agradeço pelo inestimável auxílio.

I Relatório apresentado em 1960, no $2^{\circ}$ Congresso latino-americano de direito processual, realizado na Cidade do México.

M. CAPPELLETTI, La testimonianza della parte nel sistema dell'oralità (contributo alla teoria dell'utilizzazione probatoria del sapere delle parti nel processo civile), 2 volumes. Milão: Giuffrè, 1959 (edição provisória). A edição definitiva foi lançada em 1961. 

ção e do mérito, conclusões estas que já figuraperícia e assim por diante. Absurdas e inúteis perdas de tempo, historicamente explicáveis ta, que se caía, assim, mas não menos grave excesso de formalismo. Esse excesso, que comente à obra de GERHARD ADOLF WILHELM LEONHARDT e que foi o primeiro diploma que tremismos não poderia tardar. Tampouco podeestudo de OTTO BÄHR em 1885). ${ }^{3}$ não podia racionalmente valer como critério abciosamente obrigado a não se beneficiar daquele ver qual deveria ser, em um processo não mera- quais fossem as conclusões acerca da instruvam claramente nas petições; a necessidade de ler os documentos produzidos, e até o texto da somente como reação a um método que se pretendia radicalmente abandonar, sem se dar conmeça a ser observado no Código de Processo Civil de Hannover, de 1850, devido principaladotou e tratou do princípio da giuridica inesistenza degli atti scritti, encontra-se, depois, ainda mais acentuado, no texto originário da ZPO federal germânica de 1877-1879²

Mas o insucesso, inevitável, desses exriam demorar as críticas, numerosíssimas, àqueles excessos (lembro, por exemplo, o famoso

Infelizmente, essas mesmas críticas, se tinham o mérito de demonstrar que a oralidade soluto e exclusivo, e se justamente sublinhavam o absurdo de se pretender que um ordenamento processual moderno fosse artifitão refinado e difuso meio de comunicação, que é a escrita, abstinham-se, porém, de realizar uma atenta análise de dados fenômenos, dirigida a mente formalista, a relação mais favorável de coexistência entre forma oral e forma escrita dos atos processuais.

2. Uma análise desse jaez não teria podido deixar de, em meu sentir, chegar à seguintes conclusões, aqui resumidas abreviadamente:

a) sobre a formulação-proposição da demanda bem como em relação à formulação dos seus elementos essenciais-constitutivos (petitum e conclusões; causa petendi e alegações dos fatos constitutivos do direito ou do contradireito exercido em juízo), não restam dúvidas de que, na normalidade dos casos, a forma escrita facilita a precisão, a seriedade, a identificação (puntualizzazione) da própria demanda. Esta tese é confirmada por quase todos os ordenamentos processuais modernos, os quais, tendo adotado o princípio da oralidade, todavia prescreveram, como regra geral, a forma escrita da demanda judicial, excetuando a possibilidade de as partes modificarem, integrarem e precisarem a demanda na audiência de instrução, quando isso não sirva para escopos protelatórios ou, ainda, quando se tenha dado em razão de grave negligência da parte;

b)em relação às argumentações jurídicas (técnico-jurídicas; interpretação das normas, dos negócios, dos documentos, etc.) parece não menos duvidoso que, sem negar a possibilidade de debates orais, normalmenté é muito mais séria e útil a elaboração escrita, que permite à parte, ao seu defensor, e ao próprio juiz, uma serena e meditada elaboração, permitindo um aprofundamento mediante consulta a obras científicas e jurisprudenciais, afastando o risco do emprego superficial da retórica e da improvisação, contra os esquecimentos, contra as perniciosas desigualdades derivadas do diverso grau de habilidade

${ }^{2}$ Pelas informações, a obra (extremamente criticável pela incorreta colocação do problema da oralidade) de seção I, § 22 de minha obra citada (pp.271 ss. do primeiro volume).

${ }^{3}$ Apud OTTO BÄHR, Der deutsche Civilprozess in praktischer Bethätigung, in Jhering's Jahrbücher für die Dogmatik des heutigen römischen und deutschen Privatrechts, 23 (1885), pp.339 e ss. A proposta de BÄHR foi contestada por A.WACH, in Civilprozessualische Ênquete, Ergänzungsheft da Zeitschrift für Deutschen

Revista da Faculdade de Direito da UFRGS, v. 21, Março/2002 H.G.KIP, Das sogennante Mündlichkeitprinzip, Köln-Berlin, 1952, pp.39 e ss., 58, 155 e ss. Ainda, a parte Zivilprozess, 11 (1887). e de rapidez das partes contrapostas e dos respectivos defensores, etc. Também a esse propósito, de resto, os mais coerentes códigos modernos que adotaram o princípio da oralidade não proibiram a parte de apresentar ao juiz as suas petições, nas quais possam ser expostas as argumentações jurídicas.

c) Daquilo que expus nos tópicos $a$ e $b$ teve clara consciência exatamente aquele que, a meu juízo, foi o mais profundo teórico da oralidade, ainda que não o mais feliz, conforme veremos adiante: GIUSEPPE CHIOVENDA. E consciente ele foi também, por conseqüência, do fato de que o campo no qual o princípio da oralidade podia e devia mais propriamente operar era justamente o das provas ${ }^{4}$. Mas vejamos se, porventura, também nesta matéria uma ulterior análise não se mostra, porém, necessária.

3. Examinando as provas escritas, e mais genericamente, as provas ditas pré-constituídas, podemos desde logo constatar que sua importância não foi menosprezada por nenhum ordenamento processual que soube aplicar com sucesso o princípio da oralidade. É certo que este princípio implica uma fundamental, prática e teoricamente, importantíssim revaloração da prova oral, mas esta revaloração não tem necessidade de vir acompanhada de uma irracional desvalorização da prova documental (pré-constituída), a qual, antes mesmo do processo, opera beneficamente fora dele, no mundo das relações substanciais, criando um certo grau de certeza e de confiança nos con-

sorciados em suas negociações e, em geral, nas suas relações jurídicas. É por isso que, mesmo em um ordenamento processual que esteja fundado coerentemente sobre o princípio da oralidade não apenas se explica a constante admissibilidade e importância da prova documental, como também se justifica a permanência da eficácia probatória legal das escrituras (art.2.699 e ss. do Código Civil italiano, similar em tudo ao $\S 415$ e ss. da ZPO alemã e aos §§ 292 e ss. da ZPO austríaca). É verdade que o princípio da oralidade implica a livre valoração da prova a ser constituída: mas não implica, em troca, o abandono integral da prova legal, quando esta se limite às provas pré-constituídas, as quais, repito, exercem sua eficácia (de certeza) mais antes e fora do processo do que dentro dele. Os critérios legais para a valoração da prova pré-constituída se justificam exatamente porque mediante elas os sujeitos das relações de direito material podem prever qual será o resultado em um eventual processo. Podem, assim, precaver-se contra os incertos sidera litium Podem pré-constituir, em suma, dentro de certos limites, uma garantia de segurança de suas relações. Aqui a prova legal (pré-constituída) tem mais o caráter de um fenômeno pré-processual (substancial) do que um fenômeno propriamente processual ${ }^{5}$.

Onde, ao contrário, a prova legal se justifica somente como expressão de um (antiquado) ordenamento processual escrito, mas não mais de um coerente ordenamento oral, é no campo das provas a constituir, e, por conseqüência, na área da prova lato sensu testemunhal.
${ }^{4}$ Cfr. G.CHIOVENDA, L'oralità e la prova, Riv.dir.proc.civ., ano I (1924), I, pp.5 e ss.

Recordo, como COUTURE, que com tamanha modernidade de visão estudou os problemas da prova lato sensu testemunhal e da sua liberdade para assunção e livre valoração ou sana critica do conjunto probatório, tenha também reconhecido que, ao contrário, a prova instrumental é por si mesma uma prova legal, e não de sana critica, ao menos do momento da impugnação por falsidade. In Las reglas de la sana crítica en la apreciación de la prueba testimonial, in Estudios de derecho procesal civil de E.J.COUTURE, II: Pruebas en materia civil, Buenos Aires, 1949, p.219; El concepto de fe publica, ibidem, II, cit. pp. 83 e ss. Na doutrina tedesca, H.SCHIMA, Die Prozessgrundsätze in heutiger Schau, in Scritti giuridici in memoria di Piero Calamandrei, II, Padova, 1958, p.477. 
Digo lato sensu testemunhal porque gostaria de aludir - como uma terminologia que na doutrina italiana já se encontra em MATTEO PESCATORE $^{6}$ e depois em LUIGI MATTIROLO $^{7}$ e em FRANCESCO CARNELUTTI $^{8}$, mas que tem origens muito antigas - não apenas às assertivas-narrações (de fatos, direta ou indiretamente relevantes para a causa) de terceiros, senão também àquelas provenientes das partes, sejam essas pro se declarationes, sejam, em troca, contra se declarationes.

Em relação à prova lato sensu testemunhal, os ordenamentos históricos, e ainda hoje muitos ordenamentos vigentes (não, porém, aqueles de vanguarda no progresso das reformas processuais) conhecem uma regulamentação legal que se expressa essencialmente:

a) em graves limites à admissibilidade da prova strictu sensu testemunhal (cfr. ainda hoje os arts. 2.721 e ss. do Código Civil italiano, os artigos 246-247 do nosso Código de Processo Civil; os arts. 1.341 e ss. do Code Civil francês e os arts. 268 e 283 do Code de Procédure Civile);

b)na apriorística exclusão de toda eficácia probatória da pro se declaratio da parte, salvo o dito na letra ' $c$ ';

c) na eficácia probatória vinculante da pro se declaratio jurada da parte (juramento como prova legal, admissível nos estreitos limites postos pela lei);

d)na eficácia probatória vinculante da contra se declaratio (confissão) da parte;

e) às vezes, ainda hoje, inclusive, na anacrônica persistência de absurdas normas de valoração em respeito ao testemunho de terceiros (testis unus testis nullus; in ore duorum vel trium stat veritas; e, ainda, em disposições como as estabelecidas, como era descrita em uma antiga obra atribuída a PILLIO DA MEDICINA 'ut potius sit credendum ingenuo quam libertino, seniori quam iuniori, honorato quam inferiori, masculo quam femine, etc.'

Desde logo, afirmo que tais regras foram todas, ou na sua maior parte, abolidas pelo código austríaco, desde sua formulação original de 1895. Também pelo código alemão, após as várias novelas que desembocaram na fundamental, elaborada no projeto oficial de 1931, convertido em lei em 1933, e de numerosíssimas legislações modernas, européias e fora da Europa ${ }^{10}$; ou seja, por todos os ordenamentos processuais que, ou a partir da origem (Código Kleiniano) ou nas suas modificações posteriores, adotaram, com coerência e sem excessos, o princípio da oralidade. Essas regras foram notavelmente atenuadas, mas não abolidas, no processo francês - especialmente depois de suprimir o interragatoire sur faits et articles, substituído pelo exame livre das partes (comparution personelle). Atenuadas também. mas não em medida tão considerável, no processo italiano, enquanto mais tenazmente permanecem no processo espanhol e em várias legislações latino-americanas.

${ }^{6}$ M. PESCATORE, La logica del diritto, I, Torino, 1863, pp. 80 e ss., 177 e ss.

7 LARTIROLO, Elementi di diritto giudiziario italiano, II, Torino, 1876, pp.299, 361, nota 2.

${ }^{8}$ F.CARNELUTTI, La prova civile, Roma, 1915, sub $\mathrm{n} .31$.

${ }^{9}$ Numerosas normas semelhantes poderiam ser elencadas, dentre as quais diversas categorias ou tipos de fatos jurídicos que somente poderiam ser provados, em razão do número ou da qualidade das testemunhas necessárias para a prova.

${ }^{10}$ Dediquei ao tema o segundo volume da obra citada na nota 1 .

Revista da Faculdade de Direito da UFRGS, v. 21, Março/2002
Qual é a justificativa histórica de ditas regras? Vejamos.

4. Dita justificação é dúplice, a meu sentir. Antes de mais nada, essas regras se justificam à luz de um processo dominado pela escrita. Justificam-se, ademais, ou pelo menos se explicam, sob um perfil mais geral, à luz de um sistema de pensamento contraposto àquele que bem se poderia chamar de moderno, um sistema apoiado sobre esquemas apriorísticos formalistas ao invés da direta e concreta observação dos dados. É claro, porém, que uma outra explicação são estreitamente ligadas, constituindo a primeira, no campo processual, uma manifestação da segunda, mais ampla e compreensiva.

$\mathrm{Na}$ seara das provas a constituir, a escrita significou por muitos séculos - mas não no processo clássico romano, que era baseado na oralidade - e infelizmente em algun ordenamentos ainda hoje significa, que o juiz que sentencia não tem direto e imediato contato com as partes, testemunhas e peritos. Ele julga exclusivamente com base nas petições. Ele não observa diretamente os fato probatórios, mas apenas o seu reflexo na escrita. Quais as consequêencias disso tudo?

Analisemos, em particular, a prova testemunhal. Essa, como se sabe, é uma prova 'mediata', no sentido de que o fato (a provar) representado mediante um fato (probatório) ul terior, ou seja, mediante a declaração-narração do terceiro ou da parte. Ora, ninguém duvida dos perigos - da inexatidão, da incompletude, da distorção, quiçá inconsciente, quando não culposa ou dolosa, da realidade - ínsitos à este meio de prova. A 'excelência' da prova 'imediata', mediante a qual o juiz se põe em contato direto e imediato com o fato a provar-especialmente, através da inspeção judicial - é indiscutível. Mas o que acontece com a prova testemunhal no sistema da escritura? Nesse, o juiz, além de não julgar com base na observação imediata do fato a provar, tampouco julga com base no fato (probatório) representativo do fato a provar e, sim, com base em um fato posterior quais sejam as atas e as petições, as quais, por sua vez, representam o fato representativo. Com isso, os perigos de inexatidão, da incompletude e de falsidade aumentam em progressão geométrica!

Por outro lado, há de se ter em mente que seria fruto de uma deplorável simplificação da análise considerar o testemunho como uma mera declaração-narração representativa. Em realidade, dita declaração acompanha a toda uma série de atos, de comportamentos, de dados, em suma, os quais, ainda que não propriamente representativos do fato a provar, são, porém, susceptíveis de valer como 'provas indiretas", ou seja, como indícios da veracidade da testemunha e da verdade do fato narrado por ele narrado: trata-se do modo como a testemunha narra os fatos, da subjetiva credibilidade do narrador, da objetiva verossimilhança do fato narrado etc. Esses indícios, já analisados por FRANCESCO MARIO PAGANO, na Itália, e após, por J. BENTHAM, na Inglaterra, e mais tarde por J.W. PLANCK, na Alemanha, tem muitas vezes uma tal eficácia de convencimento que deles se descurar significaria fechar os olhos para a verdade ${ }^{11}$. Mas é claro que todos ou quase todos esses indícios terminam ne-

Cfr. F.M.PAGANO, Considerazione sul processo criminale, Milano, 1801, cap.21, pp.101 (onde se observa a defesa da oralidade e da imediação na assunção da prova testemunhal, que a escritura não nos fornece os infinitos possiveis aspectos da coisa (...) Na viva voz, fala também o vulto, os olhos, a cor, o movimento, o tom da voz s modo de falar, e tantas outras diversas pequenas circunstancias, as quais modificam e desenvolvem
sentido das palavras e acrescem tantos indicios ou a favor ou contra a afirmą̧áa das palavras. Todos esses sinais se perdem na escritura, privando o juiz dos mais claros e precisos argumentos). De BENTHAM, vejase particularmente o Traité des preuves judiciaires, nas Oeuvres de J. BENTHAM (tradução francesa de Et. DUMONT), II, Bruxelles, 1829, pp.239 e ss, e, especialmente, a pp. 330 e ss., de PLANCK, Lehrbuch des Deutschen Civilprozessrechts, I, Nördlingen, $1877, \S 64$, pp.346 e ss.

Revista da Faculdade de Direito da UFRGS, v. 21, Março/2002 
cessariamente por não serem valorizados no sistema da escritura, no qual o juiz que sentencia não tem, por um lado, contato com as testemunhas e com as partes, não podendo, por outro, produzir e valorizar os importantes indícios que acompanham a narração da testemunha. Por isso, o conceito de testemunho, entendido como 'representação dos fatos', revela-se falso e irreal, fruto daquele singelo método de raciocínio, que não considera o dado fenomênico em toda sua complexa realidade.

O sistema da oralidade, aplicado no terreno das provas, e em particular nas provas a serem constituídas, assinala o momento do in gresso, também no mundo do juízo jurisdicional daquele diverso método de raciocínio, que, originado na passagem do medioevo ao renascimento, e estando sublinhado por nome como GALILEO GALIIEI BACON o fundador da escola experimental moderna, ede tantos outros pensadores e homens da ciência, encontra-se, hoje, sem dúvida, na base do conceito de juízo em geral. Este deve estar fundamentado não em apriorismos escolásticos nem em simples abstrações, mas sobre a análise fenomenológica e experimental da realidade, ta como essa se manifesta à observação. É certo que este método implica uma renovada confiança no homem, e, assim, naquilo que aqui particularmente nos interessa, no homem-juiz, nas suas capacidades de objetiva observação e de análise serena e imparcial dos dados observados. As rígidas tarifas matemáticas de valoração das provas - testis unus testis nullus, etc. eram certamente de mais fácil aprendizagem $\mathrm{e}$ aplicação do que o critério do livre convenciaplicaç o do o criterio do mento fundado na integral análise e valoração do fenômeno observado. No primeiro caso, ao juiz bastava levar em conta apenas uma ou algumas das manifestações daquele dado: por exemplo, o número de testemunhas, seu nível social, seu sexo et similia. Na segunda hipótese, ao contrário, as manifestações a serem valoradas podem ser infinitas, nem podem ser aprioristicamente indicadas e 'pesadas' pela lei.

Todavia, assim como o método de observação assinalou o recrudescimento do pensamento moderno e acompanhou renascimento da arte e da ciência, com a con- fiança do homem em si mesmo, o método de observação, naquilo que lhe foi dado adentrar no mundo do processo, portou-lhe, desde muitos séculos, o renascimento dos estudos e fervor por reformas, que ultrapassam o vetusto processo comum, expressão - seja por certos aspectos admirável e interessantíssima para os estudiosos - de uma oposta concepcão da vida e do pensamento. É natural, ademais, que tenha sido dessa forma, porque os estudos somente
podem renascer, quando o homem tenha, quiçá até pouco claramente, idéias novas para exprimir e realizar. $\mathrm{O}$ grandioso renascimento dos estudos de direito processual no século passado na Alemanha e na Áustria e em algum outro país, era justamente a expressão da consciência de que o processo (alemão) comum necessitava de reformas e de que os princípios sobre os quais se baseava eram manifestamente de métodos e idéias superadas. Daí por que as mais finas e abstratas análises dogmáticas eram, para aqueles que bem observavam, em sua substância e mais ou menos manifestamente inspiradas naquele espírito de reforma. E foi esse espírito que fez, a partir do início do nosso século, a grandeza e o mérito da escola chiovendiana. É verdade que CHIOVENDA queria uma reforma muito diversa daquela que se realizou na Itália, com o código de 194 com código de confronto do projeto chiovendiano com o código hoje vigente. Mas justamente porque esse código em muitos pontos se afastou da idéia, corretamente estabelecida, da oralidade - de um lado, foram conservados institutos como o do juramentoprova legal, de outro, criando ins obstaculizavam a imediação, como o princípio do juiz instrutor, e assim por diante - justamente por isso, a meu juízo, esse código não teve nem poderá ter o sucesso, que, por outros aspectos, poderia ter merecido. Mas aquilo que não foi feito, poder-se-á, ou melhor, dever-se-á como o despertar dos estudos, que, no século passado, aconteceu principalmente nos países de língua alemã, tenha atingido a Itália e tantos outros países latinos. E este é um sinal seguro que permite antever a reforma dos ordenamentos processuais.

\section{Democracia e Cidadania}

no Brasil

\author{
Dr. Miguel Reale Gúnior
}

Professor Titular da Universidade de São Paulo

\section{1 - O Público e o Privado}

O tema "democracia e cidadania no Brasil" faz aflorar as contradições mais contundentes que caracterizam a história de nosso país. Desde a independência de Portugal, em 1822 vigora uma endêmica instabilidade política baixo índice de real exercício da cidadania por parte da maioria da população, ao lado de um discurso liberal que se contenta, todavia, mais com a coerência das idéias do que com a sua efetividade.

De forma inusitada combinam-se a estrutura estamental da sociedade brasileira e a sua provisoriedade e instabilidade ${ }^{1}$, conduzindo à sensação esquizofrênica de contínua exisência de duas realidades que convivem, malgrado aparentemente sejam inconciliáveis.

A principal razão de ser desta antinomia está em nossa estrutura escravocrata ${ }^{2}$. O liberal-escravismo deixou profundas marcas na forma de ser da sociedade brasileira, em estranha comunhão da defesa intransigente das liberdades políticas, pelas mais diferentes lideranças durante o império, com a concomitante e arraigada justificação "patriótica" da escravidão, o

' Assim assinala NOVAIS, Fernando, para o qual a sociedade colonial estratificava-se de forma estamental e apresentava intensa mobilidade, pois o senhor, dono de terras e de outros homens, os escravos, deveria ser um industrial e comerciante, produzindo para vender para fora, vivenciando uma situação de ambiguidade, in Condições da privacidade na colônia, na coletânea, "História da vida privada no Brasil, 1, São Paulo, Companhia das Letras, 1998, p. 30 e seguinte.

${ }^{2}$ Destaco três ambiguidades que ferem fundo a sensibilidade da sociedade brasileira, e que decorrem da ordem escravocrata: a primeira, com a manutenção da condição de escravo do filho do senhor havido com sua escrava, entendimento este prevalecente em nossos tribunais, malgrado a luta contra esta orientaçāo empreendida pelo Instituto dos Advogados, em especial por PERDIGÁO MALHEIRO; a segunda: a circunstância por vezes verificada do filho alforriado ter por escrava a mãe recebida em herança, caso relatado por SLENES, Robert W, em Senhores e subalternos no oeste paulista, na coletânea "História da vida privada" , 2 , São Paulo, Companhia das Letras, 1998, p. 234 e seguintes. A terceira ambiguidade, vivida em razão da prática de capoeirage $\mathrm{m}$ por parte de negros libertos por terem se alistado no Exército, e que ao retornarem da guerra do Paraguai, como heróis de pátria, não poderiam ser presos como vadios. A sociedade devia a eles negros a vitória no campo de batalha, mas não lhes outorgava cidadania e condição de igualdade jurídica e moral, apesar de se constranger em puní-los por vadiagem, forma pela qual se reprimia a capoeiragem. SOARES, CARLOS ALBERTO LIBANO, A negragada instituição, as capoeiras no Rio de Janeiro, Coleção Biblioteca Carioca,, Rio, 1994 